\title{
Use of Rhea americana egg yolk in substitution to chicken egg yolk in equine semen extenders
}

\author{
Liana de Salles van der Linden', Ivan Cunha Bustamante-Filho3, Santiago Duglio Schiavo², Márcio André P. Maciel, Murilo Farias \\ Rodrigues ${ }^{7}$, Sergio Ivan dos Santos ${ }^{2}$, Rodrigo Costa Mattos ${ }^{1}$ and Adriana Pires Neves ${ }^{1,2}$ \\ 1 REPROLAB, Faculdade de Veterinária, UFRGS, Porto Alegre, Brazil \\ 2 Faculdade de Zootecnia, Unipampa, Dom Pedrito, Brazil \\ ${ }^{3}$ Centro Universitário UNIVATES, Lajeado, Brazil
}

\begin{abstract}
Summary: The aim of this study compared the use of two commercial equine semen extenders supplemented with chicken egg yolk or Rhea americana egg yolk as a lipid source. Ejaculates from six Criollo stallions were visually and microscopically evaluated. Semen samples were divided in two aliquots and diluted in centrifugation extender. Each aliquot was mixed with 2 different commercial semen extenders with chicken or Rhea egg yolk for further cryopreservation. All the thawed samples were checked for total and progressive motility, physical and functional membrane integrity (HOST test and CFDA-PI fluorescence) 1 week or more after cryopreservation. The best results were observed between the commercial semen extenders but there was no strong evidence of Rhea egg yolk to enhance total and progressive sperm motility. However, Rhea egg yolk as an alternative lipid source improved the sperm membrane functionality in both commercial equine semen extenders. The use of Rhea egg yolk might be a good replacement to supplement commercial equine semen extenders.
\end{abstract}

Keywords: cryopreservation / equine semen / egg yolk / reproduction

Correspondence: Prof. Dr. Adriana Pires Neves, Assistant Professor, UNIPAMPA, School of Animal Science, Rua 21 de Abril, 80, Dom Pedrito, RS, 96450-000,Brazil. E-mail address: adripneves@yahoo.com.br

Citation: de Salles van der Linden L., Cunha Bustamante-Filho I., Duglio Schiavo S., Peres Maciel M. A., Farias Rodrigues M., dos Santos S. I., Mattos R. C., Pires Neves A. (2014) Use of Rhea americana egg yolk in substitution to chicken egg yolk in equine semen extenders. Pferdeheilkunde 30, 61-64

\section{Introduction}

The artificial insemination with frozen semen in horses still has some piffalls that require attention due to individual variations, low dose yield per ejaculate, higher cost per pregnancy and, the low pregnancy rates when compared with fresh or refrigerated semen (Ball 1998, Backman et al. 2004). The sperm cell suffers great stress during freezing and thawing steps because the semen temperature drops from room temperature to $8 \mathrm{C}$ and the next step, from $-15^{\circ} \mathrm{C}$ to $-60^{\circ} \mathrm{C}$ (Mazur 1984). This can be minimized using semen extenders which protect the sperm cell during cryopreservation. Aurich (2005) mentioned undefined semen extender composition limits the understanding of good or poor semen evaluation results during refrigeration.

Egg yolk has been used in semen extenders for years as a source of lipids, aiming to reduce the sperm membrane damage. It is one of the main components of equine semen extenders, used in concentrations from 2.5 to 25 (Sieme 2011) because it protects cell membrane against thermic shock (Parks and Graham 1992, Sieme 2011 ). The mechanism is an interaction between low- and high- densitylipoproteins which the low-density protein (LDL) acts a protective film in the cell surface (Mayer and Lasley 1945, Parks and Graham 1992, Amann and Graham 1993, Watson 1995). LDL has properties to stabilize the membrane and neutralize harmful components of seminal plasma against the sperm cell (Aurich 2005).

The cholesterol from egg yolk also helps in the membrane stabilization of spermatozoa. The lack of this lipid source has strong effect in the sperm membrane reorganization and protein membrane fusion (Amann and Graham 1992, Gadella et al. 2001, Gadella and Colenbrander 2003, Cross 1998). The higher proportion of cholesterol:phospholipids in plasma membrane promotes superior stability that might increase viability and longevity of spermatozoa (White 1993, Cross 1998).

In the past years, egg yolks of several bird species have been tested as a substitute of chicken egg yolk for semen extenders due to distinct concentrations of lipids and proteins. Humes and Webb (2006) demonstrated that the use of Alectoris chukar egg yolk as semen extender component had higher total and progressive sperm motility when compared to chicken egg yolk. Another study used duck egg yolk (Anas platyrhynchos domesticus) as water buffalo semen extender component which exhibited higher post-thaw sperm motility with few sperm defects compared to chicken egg yolk (Andrabi et al. 2008). In South America, the native bird Rhea Americana is quite abundant and farm-raised for meat, eggs and leather. The egg size (600 grams) and the capability to find them locally encouraged to test this egg yolk as equine semen extender. This study compared the use of two commercial semen extenders using chicken or Rhea egg yolk as lipid source.

\section{Materials and Methods}

Two ejaculates from 16 Criollo stallions were screened before and after cryopreservation for this experiment. The semen 
was collected using Hannover model artificial vagina (Götze 1949) and one restrained mare in estrus was used as a phantom. Stallions were kept in individual barns at stud farms located at Rio Grande do Sul State, Brazil. Based on the initial results, six stallions were chosen for the study. Six ejaculates from each stallion were collected in the local farms. The cryopreservation process was performed at Laboratório de Reprodução Animal (PROREP), Universidade Federal do Pampa (Dom Pedrito, RS). The post-thawing analysis were finalized in the Laboratório de Reprodução Animal (REPROLAB), Universidade Federal do Rio Grande do Sul (Porto Alegre).

The semen evaluation was assessed visually (gel volume, gel-free volume, aspect) and microscopically (total and progressive motility; concentration, morphology). After evaluation, samples were diluted $1: 1$ in centrifugation extender (FR1, Nutricell, São Paulo, Brazil), and centrifuged at $400 \times \mathrm{g}$ for $10 \mathrm{~min}$. $90-95 \%$ of the supernatant (extender plus seminal plasma) was discarded. All samples were split in four aliquots and re-suspended to a final concentration of $200 \times 10^{6} \mathrm{sperm} / \mathrm{mL}$. Each aliquot was mixed individually with commercial extender A (glycerol as cryoprotectant) + chicken egg yolk, commercial extender B (methylformimide as cryoprotectant) $+20 \%$ chicken egg yolk , commercial extender A $+20 \%$ Rhea egg yolk and commercial extender B (methylformimide as cryoprotectant) + Rhea egg yolk (Figure 1).

The semen samples were packed into $0.5 \mathrm{ml}$ straws (IMV International Corporation, Minneapolis, MN, USA), cooled at $4{ }^{\circ} \mathrm{C}$ for $20 \mathrm{~min}$, and frozen $4 \mathrm{~cm}$ above liquid nitrogen level for $20 \mathrm{~min}$ before stored in liquid nitrogen $\left(-196^{\circ} \mathrm{C}\right)$. All the aliquots were checked for total and progressive motility, physical and functional membrane integrity (HOST test and CFDA-PI fluorescence) at least 1 week after freezing. The results were analyzed using $2 \times 2$ factorial design followed by Bonferroni test (Prism 5, GraphPad, USA).

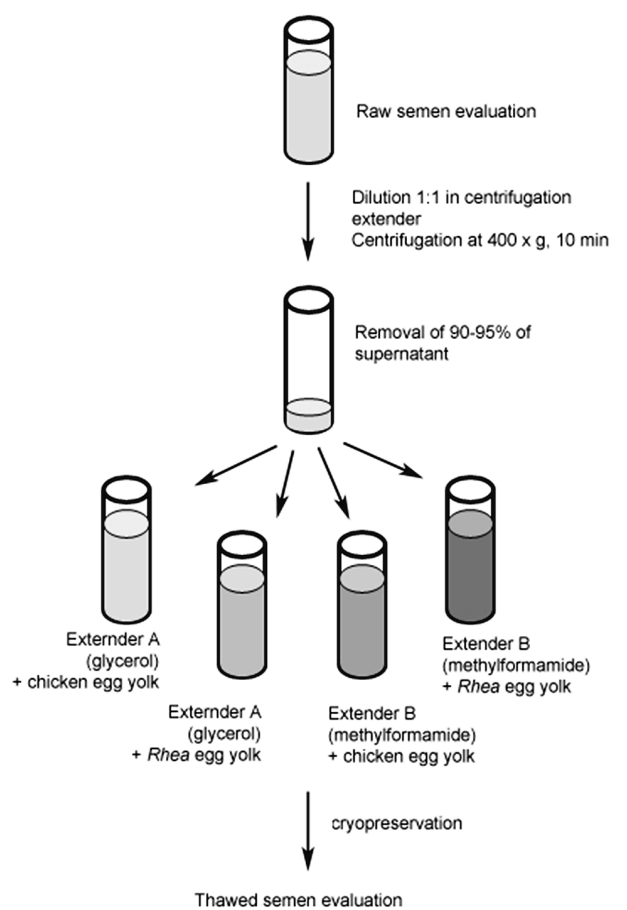

Fig. 1 - Schematic representation of the experimental design / Schema des Versuchsaufbaus.
Fig. 2 - Effect of extender and egg yolk type on total and progressive motility and membrane functionality and integrity of Criollo horses cryopreserved semen. ${ }^{* * *} p<0.001,{ }^{* *}$ means $\mathrm{p}<0.01 ; \mathrm{a}, \mathrm{b}$ means $\mathrm{p}<0.05$. / Auswirkung von Verdünner- und Eigelbart auf die Gesamt- und Vorwärtsbewegung sowie die Funktionalität und Integrität der kryokonservierten Samen der Criollohengste. *** $p<0,001,{ }^{* *} p<0,01, a, b, p<0,05$
A

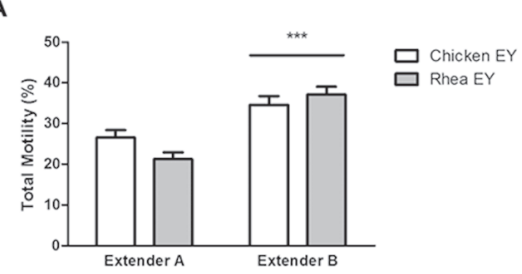

C

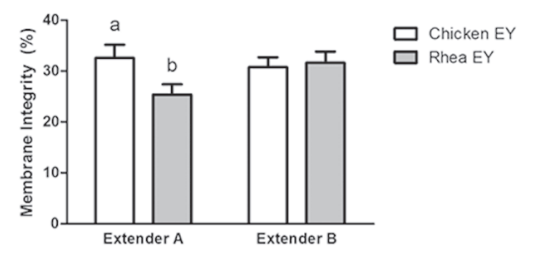

B

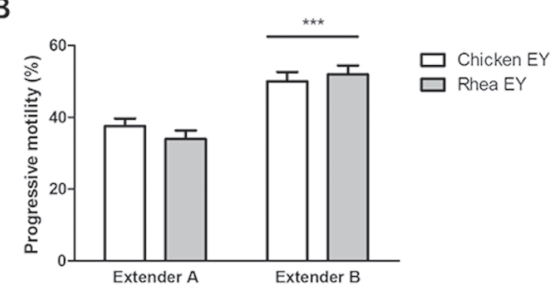

D

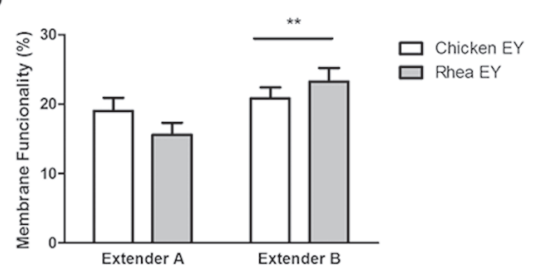

Table 1 - semen characteristics from Criollo stallions.

\begin{tabular}{|c|c|c|c|c|c|c|}
\hline Stallion & $A$ & B & $\mathrm{C}$ & $\mathrm{D}$ & $E$ & $\mathrm{~F}$ \\
\hline Number of ejaculates & 6 & 6 & 6 & 6 & 5 & 5 \\
\hline Volume & $31,2 \pm 9,2$ & $28,16 \pm 11,8$ & $19,5 \pm 12,1$ & $80,2 \pm 32,4$ & $49,8 \pm 5,6$ & $91,8 \pm 69,5$ \\
\hline Concentration $\left(\times 10^{6}\right.$ & $243 \pm 45,7$ & $114,5 \pm 16,2$ & $84,5 \pm 41,8$ & $72,8 \pm 13,4$ & $274 \pm 38,5$ & $192,2 \pm 89$ \\
\hline TNS (x $\left.10^{9} \mathrm{spz} / \mathrm{mL}\right)$ & $7,88 \pm 3,43$ & $3,22 \pm 1,38$ & $2,89 \pm 2,1$ & $5,65 \pm 1,79$ & $13,67 \pm 2,57$ & $17,13 \pm 11,91$ \\
\hline TM (\%) & $78,4 \pm 15$ & $80 \pm 17,7$ & $73,4 \pm 17,3$ & $65 \pm 12,7$ & $82 \pm 8,4$ & $85 \pm 5$ \\
\hline MP (\%) & $61,7 \pm 9,8$ & $65 \pm 12,2$ & $56,7 \pm 12,1$ & $48,3 \pm 7,5$ & $62 \pm 8,4$ & $65 \pm 5$ \\
\hline
\end{tabular}

TNS - total number of sperm; TM - total motility; PM - progressive.motility 


\section{Results}

The ejaculates for cryopreservation had total sperm motility between 65 to $85.5 \%$, and progressive motility between 48.3 to $65 \%$ (Table 1). After the cryopreservation process, the commercial extender B (methylformimide as cryoprotectant) with either chicken egg yolk or Rhea egg yolk showed better results fortotal and progressive motility and membrane functionality $(P<0.001$, Figure 2$)$. On the other hand, the membrane integrity in the semen frozen with glycerol (extender A) and chicken egg yolk had greater percentile than with Rhea egg yolk $(P<0.05)$.

\section{Discussion}

In the present work we tested the possibility of Rhea americana egg yolk as lipid source for equine semen extender. Our results showed that Rhea egg yolk can be used as a replacement of chicken egg yolk for stallion semen methylformamide based-extender for cryopreservation. However there is a significant reduction in sperm membrane integrity when a glycerol-based semen extender is employed associated with Rhea egg yolk. Perhaps, an intrinsic component of Rhea egg yolk might have a deleterious effect on sperm membrane, possibly an excess of polyunsaturated fatty acids (PUFA). Wang et al. (2000) and Navarro (2001) described a ratio PUFA/SFA (saturated fatty acid) three times greater in Rhea egg yolk in comparison to chicken egg yolk. This fact suggests that the use of this lipid source in equine semen extender may increase oxidative stress, since higher concentration of PUFA potentializes the formation of reactive oxygen species (Sanocka and Kurpisz 2004).

Rhea egg yolk has an augmented concentration of different lipid molecules in contrast to chicken, such as arachidoc acid (2.4 times greater), linoleic acid (5.28 times greater) and oleic acid (2.28 times greater). These PUFA might be associated to the sperm membrane and they probably trigger a chain reaction of lipid peroxidation events. Some animal species with higher PUFA content in sperm membrane are more susceptible to lipid peroxidation. Awda et al. (2009) described wild boar semen is more susceptible to oxidative stress due to higher PUFA content in membrane and to a reduced antioxidant capacity in seminal plasma.

The frozen semen parameters found in this study confirmed the superiority of amides-based extenders in comparison to glycerol-based extenders, as described elsewhere (Gomes 2002, Papa et al. 2002, Terraciano et al. 2008). It is reasonable to suggest that the benefits provided by the cryoprotectant overcome the importance of the cryopreservation extender lipid composition. In fact, it was proposed that the importance of the lipid fraction of a given extender is due to its ability to bind to Binder of Sperm Proteins (BSP) from seminal plasma (Manjunath et al. 2007). This class of proteins, in the horse known as HSP1 and HSP2 (Manjunath et al. 2009), induce changes in the sperm membrane by stimulating cholesterol and phospholipids efflux. Consequently, the lipids in the extender compete with sperm membrane fatty acids, abolishing the detrimental effects of BSP proteins on sperm cell (Manjunath et al. 2007). Thus, the lipid profile of the extender might not be so important, as long as the extender has a lipid component to protect the sperm membrane from fatty acid efflux.

This work provides evidence that Rhea americana egg yolk can be used as a substitute for chicken egg yolk in semen extenders with methylformamide, however without increase in semen quality.

\section{Acknowledgements}

The authors would like to thank to Luciana Meirelles Richer (DVM) for the English language revision; and to the farms which provided the animals.

\section{References}

Amann R. P. (1991) Fertility of cryopreserved sperm. Contraception Fertilite Sexualite, v. 19, p.946-954

Amann R. P., Graham J. K. (1993) Spermatozoal function. In: McKinnon A. O., Voss J. L. (Ed.). Equine reproduction. Philadelphia: Lea \& Febiger, 1993. p. 715-745

Aadrabi S. M. H., Ansari M. S., Ullah N., Aawar M., Mehmood A., Akhter S. (2008) Duck egg yolk in extender improves the freezability of bufalo bull spermatozoa. Anim. Reprod. Sci. 104, 427-433

Aurich C. (2005) Factors affecting the plasma membrane function of cooled-stored stallion spermatozoa. Anim. Reprod. Sci. 89, 65-75

Aurich J. E.; Schönherr U., Hoppe H., Aurich C.(1997) Effects of antioxidants on motility and membrane integrity of chilled-stored stallion semen. Theriogenology 48, 185-192

Awda B. J., Mackenzie-Bell M., Buhr M. M. (2009) Reactive oxygen species and boar sperm function. Biol. Reprod. 81, 553-561

Backman T., Bruemmer J. E., Graham J. K., Squires E. L. (2004) Pregnancy rates of mares inseminated with semen cooled for 18 hours and then frozen. Animal Sci. 82, 690-694

Ball B. A. (1998a) An introduction to the use and application of cryopreserved equine semen. In: Equine Assisted Reproductive Technology Workshop 1998, Davis. Proceedings p.25-41

Cross N. L. (1998) Role of cholesterol in sperm capacitation. Biol. Reprod. 59, 7-11

Dell'Aqua jr. J. A.; Papa F. O.; Alvarenga M. A., Zahn F. S (2001) Effects of warming rate on sperm parameters and insemination site and dose on the fertility of equine frozen semen. Anim. Reprod. Science 68, 344-345

Gadella B. M. Colenbrander B. (2003) Bicarbonate dependent capacitation of mammalian sperm cells: a comparative overview. In: Proceeding of a workshop on transporting gametes and embryos 12, Brewster, Massachusetts, p. 43-48

Gadella B. M., Rathi R., Brouwers J. F. H. M. et. al. (2001)Capacitation and acrossome reaction in equine sperm. Anim. Reprod. Sci. 68, 249-265

Gomes G. M., Papa F. O., Jacob J. C. F., Macedo L. P.; Leão, K. M., Machado M. S., Alvarenga M. A. (2002) Melhoria dos parâmetros espermáticos pós-descongelação com meio MP-50 para sêmen de garanhões da raça mangalarga marchador. Revi. Brasil. Reprod. Anim. 26, 187-189

Götze R. (1949) Besamung und Unfruchtbarkeit des Haussäugetieres. Hannover: Schaper Verlag

Humes R., Webb G. (2006) Use of chicken or chukar egg yolk with two cryoprotectants for preservation of stallion semen. Anim. Reprod. Sci. 94, 62-63

Loomis P R. (2006) Advanced Methods for Handling and Preparation of Stallion Semen. In: Carnevale E.M. Vet. Clin. North Am. Equine Pract. 22, 663-676

Maciel M (2012) Criação de Cavalo Crioulo movimenta mais de R\$ 1,28 bi. Jornal do Cavalo Crioulo. Publicação Oficial da ABCCC.

Manjunath P., Lefebvre J., Jois P. S., Fan J., Wright M. W. (2009) New Nomenclature for BSP genes. Biol. Reprod. 80, 394-397. doi: 10.1095/biolreprod.108.074088. Epub 2008 Oct 15. Review 
Manjunath P., Bergeron A., Lefebvre J., Fan J. (2007) Seminal plasma proteins: functions and interaction with protective agents during semen preservation. Soc. Reprod. Fertil. Suppl. 65, 217-228

Mayer D. T., Lasley J. F. (1945) The factor in egg yolk affecting the resistance, storage potentialities, and fertilizing ability of mammalian spermatozoa. Anim. Sci. 4, 261-269

Mazur P. (1984) Freezing of living cells: mechanisms and implications. Am. J. Physiol. 247, .125-142

Papa F. O., Zahn F. S., Dell'Aqua ir.,J. A., Alvarenga M. A. (2002) Utilização do diluente MP 50 para criopreservação de sêmen equino. Rev. Brasil. Reprod. Anim. 26, 184-187

Parks J. E., Graham J. K. (1992) Effects of cryopreservation procedures on sperm membranes. Theriogenology 38, 209-222

Sanocka D., Kurpisz M. (2004) Reactive oxigen species and sperm cells. Reprod. Biol. Endocrinol. 2, 1-7,

Sieme H. (2011) Semen extenders for frozen semen. Equine Reproduction 2nd edition, v.2, p. 2964-2971
Terracino P. B., Bustamente Filho I. C., Miquelito L. V., Arlas T. R. Castro F., Mattos R. C., Passos E. Q., Oberst E. R., Cirne Lima, E. $O$. (2008) Criopreservação de espermatozóides eqüinos comparando duas curvas de congelamento combinadas com diluentes comerciais: uma análise laboratorial. Ciência Rural 38

Vidament M., Dupere A. M., Julienne P., Evain A., Noue P., Palmer E. (1997) Motility and fertility of stallion semen frozen with glicerol and/or dimethyl formamide. Theriogenology 48, 907-917

Wang Y., Sunwoo H., Cherian G., Dlim J. L. (2000) Fatty Acid determination in chicken egg yolk: A comparison of different methods. Poultry Sci. 79, 1168-1171

Watson P. F. (1995) Recent developments and concepts in the cryopreservation of spermatozoa and the assessment of their post-thawing function. Reprod. Fertil. Develop. 7, 871-891

White I. G. (1993) Lipids and calcium uptake of sperm in relation to cold shock and preservation: a review. Reprod. Fertil. Develop. 5, 639-658

\title{
Zusammenfassung
}

Ziel dieser Studie war es, den Einsatz von zwei kommerziellen equinen Spermaverdünnern ergänzł durch Hühnereigelb oder Nandu-Eigelb als Lipidquellen zu vergleichen. Ejakulate von sechs Criollo Hengsten wurden visuell und mikroskopisch ausgewertet. Die Samenproben wurden in zwei Aliquots aufgeteilt und verdünnt. Jedes Aliquot wurde mit zwei verschiedenen kommerziellen Samenverdünnern mit Hühner- oder Nandueigelb für die weitere Kryokonservierung gemischt. Alle aufgetauten Proben wurden hinsichtlich der Gesamt- und progressiven Motilität sowie physikalischer und funktioneller Integrität der Membran (HOST Test und CFDA -PI Fluoreszenz) eine Woche oder länger nach der Kryokonservierung überprüft. Die besten Ergebnisse wurden zwischen den kommerziellen Samenverdünnern beobachtet, aber es gab keine stichhaltigen Beweise dafür, dass Nandueigelb die Gesamt- und progressive Motilität der Spermien erhöht. Allerdings verbessert Nandueigelb als alternative Lipidquelle die Membranfunktionalität der Spermien bei beiden kommerziellen equinen Spermaextendern. Die Verwendung von Nandueigelb könnte ein guter Ersatz zur Ergänzung kommerzieller equiner Spermaverdünner sein.

Schlüsselwörter: Kryokonservierung / equines Sperma / Eigelb / Reproduktion

8th ICERM Abstract

\section{Oestrus suppression in mares by intrauterine glass spheres}

\author{
V. Waltt', K. Müller', H.-A. Schoon', M. M. Rivera del Alamo², T. Katila ${ }^{3}$ \\ ${ }^{1}$ Institute of Pathology, Faculty of Veterinary Medicine, Leipzig University \\ 2 Unit of Reproduction, Faculty of Veterinary Medicine, Barcelona (Spain) \\ ${ }^{3}$ Department of Production Animal Medicine, Faculty of Veterinary Medicine, Helsinki (Finland) \\ Correspondence: Veronika Waltl, Institut für Veterinär-Pathologie, Leipzig. E-mail: v.waltl@gmx.de
}

\section{Introduction}

Intrauterine devices (IUDs) consist of plastic or metal and are inserted through the vagina into the uterus. They are used to prevent pregnancy in human females and other species (rabbit, rat, cow). In sports mares intrauterine devices additionally are utilized to suppress unwanted signs of oestrus behaviour during competition. Mares and stallions are showed at national and international equestrian competition to present their quality. For breeders it is of interest that stallions but also mares have proven themselves in sports and if they are capable of passing their qualities to the offspring. In this context sporting performance of mares become more important. Mares are long-day, seasonally polyoestrous animals and consequently undergo cycling reproductive activity. As owner and trainers have difficulties in training or riding mares during oestrus, they ask for options to suppress the oestrus behaviour. The use of intrauterine glass balls is easy, inexpensive and minimal invasive. As well it avoids daily administration of hormones and is not doping-relevant. The presence of foreign body in the uterine cavity (IUD) is known to interfere with reproduction in all species tested to date, but the mechanism of action has not been fully elucidated. It is generally accepted that IUDs produce a sterile inflammatory reaction caused by the presence of a foreign body in the uterus as a local effect. In cows, rabbits and ewes also a systemic effect involving the utero-ovarian-pituitary axis has been supposed. The oestrus suppression in mares by intrauterine glass spheres is caused by prolonging primary luteal function. But the biological mechanism is still unknown. However, hypotheses such as pseudopregnancy, placebo effect for mare owners and chronic inflammation are discussed.

\section{Material and Methods}

For the study 30 mares were subdivided into four groups (G): $G 1$ : Al, pregnant ( $n=8$ ); $G 2$ : Al, non-pregnant (cycling) ( $n=7$ ); $G 3$ : IUD, prolonged luteal phase ( $n=7)$ - IUD-P (IUD-Positive); G4: IUD, luteal phase of regular length ( $n=8)-I U D-N(I U D-N e g a t i v e)$. Pregnancy status was verified with transrectal ultrasonography. Biopsies were taken on day 15 post-ovulation. Progesteron values for IUD-P mares were below $10 \mathrm{ng} / \mathrm{ml}$ in contrast IUD-N animals showed progesterone concentration above $10 \mathrm{ng} / \mathrm{ml}$. The aim of this immunohistochemical study was to investigate the expression pattern of different enzymes, uterine proteins and hormone receptors in endometrial biopsies of mares with IUDs, compared to the expression in mares after artificial insemination (Al). Furthermore the endometrial biopsy samples were analyzed for the number of inflammatory cells (neutrophils, eosinophils, mast cells, lymphocytes and 
macrophages). For analysis of the results the statistical package SPSS (SPSS Software-GmbH Munich) was used. Significance between the groups (Kruskal-Wallis test/Mann-Whitney $U$ test) was attributed at $\mathrm{P}<0.05 / 0.0125$.

\title{
Results
}

The mares in group 1 (Al, pregnant) were younger in comparison with non-pregnant Al-animals (G2). Also IUD-mares with extended luteal function (G3) were younger than IUD-N-horses (G4). Inseminated but non-pregnant mares (G2) were characterized by a distinctive Uteroferrin (UF)- and COX-2 expression, while Uterocalcin (UC) was at a low level. In pregnant mares (G1) the UC-expression was maximal, whereas only a weak immunolabelling for UF could be detected. Moreover, the expression of COX-2 was detectable in IUDmares $(G 3, G 4)$ but not in pregnant mares $(G 1)$. In summary, inseminated mares $(G 1, G 2)$ showed the expected expression patterns correspondent to their reproductive cycle. In contrast IUD-animals $(G 3, G 4)$ revealed a variable COX-2, UF and UC expression. No significant difference of Uteroglobin-expression and Ki-67-expression (proliferation marker) could be determined between the groups. Mares with prolonged luteal phase (G1: Al, pregnant; G3: IUD-P) and high progesterone concentration in the serum showed lower oestrogene- and progesterone-receptor-expression in comparison to mares with regular luteal phase (G2: Al, cycling; G4: IUD-N) and oestrogen dominance. No significant differences occurred between the numbers of neutrophils, eosinophils, mast cells and lymphocytes in the endometrial samples of the groups. In the stratum compactum total numbers of macrophages in $\mathrm{G} 1$ (Al, pregnant) were significantly higher than in $\mathrm{G} 2$ (Al, cycling), there was also a numerical increase in numbers of macrophages among $\mathrm{G} 4$ to $\mathrm{G} 3$, but the difference was not statistically significant.

\section{Discussion}

The endometrial changes of the immunolabelling for proteins and COX-2 in the IUD-mares compared to Al-mares confirm that the effect of intrauterine glass spheres on the behaviour of the mare cannot be explained by a placebo effect. As pregnant mares and IUDmares with prolonged luteal phase showed a significantly different expression pattern for COX-2 and UF ( $p<0.01$ ) it can be supposed, that pseudopregnancy in IUD-mares with prolonged luteal phase is unlikely. A foreign body reaction is composed of macrophages and an end-stage response of inflammatory responses following implantation of medical device. The higher number of these cells in $\mathrm{G} 3$ (IUD-P) could be indicative for a local effect (foreign body reaction) of IUDs in horses, but data of chronic inflammation in the equine endometrium are rare. As the uterine susceptibility to infection varies between mares (resistant/susceptible mares), this could explain the low efficiency of IUDs to suppress signs of oestrus (IUD-P: $n=7$; IUD-N: $n=8$ ). Possibly the age of the mare is relevant for efficiency as well, as IUD-P are younger than IUD-N animals and NIE et al. (2003) observed a similar age-related distribution. The mechanism of inhibiting luteolysis by IUDs is still unknown. Further studies are necessary to survey a possible systemic effect of IUDs affecting the cycle length in mares.

\section{New insights into the pathogenesis of equine endometrosis? The role of periglandular mononuclear cell infiltrates in the endometrium of mares}

\author{
K. Klose, H.-A. Schoon \\ Institute of Pathology, Faculty of Veterinary Medicine, University of Leipzig, Leipzig, Germany \\ Correspondence: Kristin Klose, Institut für Veterinär-Pathologie, Universität Leipzig, An den Tierkliniken 33, 04103 Leipzig, Germany. \\ E-Mail: kristin.klose@vetmed.uni-leipzig.de
}

\section{Introduction}

Aetiopathogenesis of endometrosis in the endometrium of mares has not been clarified completely by now. Endometritis or at least inflammatory cell infiltration were among others considered to be one of the triggering factors of equine endometrosis. During the routine histopathological assessment of endometrial biopsies of mares inflammatory cell infiltrates around endometrial glands can be noticed from time to time, but nevertheless regularly. However the relevance of these cell infiltrates has not been studied yet and their importance in the endometrial context is unknown. Therefore the main objective of this study was to detect these periglandular inflammatory foci and analyse their occurrence in matters of frequency and seasonality as well as to determine the clinical and endometrial status of the affected mares. In particular a potential influence of these periglandular accentuated cell infiltrates on early stages of equine endometrosis and/or on the progression of existing endmetrotic alterations should be examined.

\section{Material and methods}

All biopsies examined in routine diagnostics during $2009(n=754)$ were retrospecitvely scanned for inflammatory cells accentuated around endometrial glands. 133 biopsies with one or more than one of these periglandular inflammatory foci could be found out. These biopsies were histopathologically examined by H/E-staining. For further investigations all selected slides were stained with Methylgreenpyronin-staining (detecting plasma cells) and were examined by means of immunohistochemistry (CD 3, CD 79A, MAC 387 [differentiating inflammatory cells]; laminin [marking basal lamina]; vimentin, desmin, a-smooth-muscle-actin (a-SMA) [marking intermediate filaments in epithelial and stromal cells]).

\section{Results}

The periglandular cell infiltrates occurred in samples taken throughout the whole year without any particular seasonal changes in frequency. Inflammatory cells around endometrial glands could be detected in about $15 \%$ to $20 \%$ of the biopsies in each month. Including 
the mares' individual data no connection to age or parity of the examined mares could be observed. On average the affected mares are 15 years old and gave birth to 2 foals. Periglandular cell infiltrates consisted mainly of mononuclear cells and often occurred simultaneously to concurrent endometrosis and/or endometritis. Samples without any pathological signs could also be found. Occasionally infiltration of inflammatory cells into the glandular epithelium could be noticed. The majority of the selected biopsies with periglandular inflammatory foci exhibit also endometrotic lesions with varying characteristics in quantity and quality. Only 13 of the 133 biopsies do not show any signs of periglandular fibrosis. Periglandular accentuated inflammatory cells are attached around "healthy" endometrial glands as well as around or adjacent to glands affected by periglandular fibrosis. In more than half of the selected samples ( $\mathrm{n}=84$ ) the endometria show an endometritis. Mostly a mild endometritis can be found (67\%). Beside lymphoplasmacellular endometritis (71\%) there are also suppurative and mixed-cellular inflammatory alterations as well as in one case an eosinophilic endometritis. It could be noticed that the involved inflammatory cell population is always dominated by T-lymphocytes. Plasma cells, B-lymphocytes and macrophages take also part in the periglandular accentuated inflammation, but in smaller numbers. Thereby plasma cells occur in a moderate number whereas B-lymphocytes and macrophages could only be rarely found within the periglandular inflammation cell population. The underlying glandular basal lamina of the affected glands was altered in almost each localisation. In such cases the basal lamina seemed to be swollen or it even appeared discontinuous. In glandular epithelial cells expression of vimentin could be found rarely. Endometrial stromal cells surrounding affected glands showed rarely an expression of desmin and regularly an expression of a-SMA.

\title{
Discussion
}

Periglandular accentuated mononuclear cells often occur in altered equine endometria. However the endometrial glands surrounded by inflammatory cells show in most cases no obvious signs of endometrosis. Likewise the periglandular infiltration does not seem to be associated to an endometritis, as the dominating cell population within the periglandular accumulation of inflammatory cells is always composed of T-lymphocytes, in spite of the character of concurrent endometritis (e.g. lymphoplasmacellular, suppurative, mixed-cellular). In stromal cells, surrounding the affected endometrial glands the expression patterns of the intermediate filaments (vimentin, desmin, a-SMA) are comparable to those in early stages of equine endometrosis. Consequently the periglandular accumulation of mononuclear cells around endometrial glands associated with basal lamina alterations could be interpreted as one of the triggering factors of equine endometrosis. It is conceivable that the damage of the basal lamina leads to the development of a periglandular fibrosis in terms of reparation. In further studies the cause for the accumulation of inflammatory cells around endometrial glands and the infiltration into the glandular epithelium has still to be determined.

\section{Analysis of reproductive disorders in performance mares using the endometrial biopsy as a diagnostic tool}

\author{
H. Kilgenstein, S. Schöniger, H.-A. Schoon \\ Institute of Veterinary Pathology, Faculty of Veterinary Medicine, University Leipzig \\ Correspondence: Helen Kilgenstein, Institute of Veterinary Pathology, Faculty of Veterinary Medicine, University Leipzig. E-mail: helenkilgenstein@gmx.de
}

Similar to human female athletes, temporary subfertility can be observed in performance mares that recently completed their career in sports. In contrast after having bred once, they conceive the next time quite easy. In human female athletes it is known, that intensive physical workout affects the ovarian function. It has been recognized, that the microscopic examination of an endometrial biopsy can reveal glandular alterations that are indicative for the presence of an ovarian dysfunction. Therefore, the objective of this study was the histopathological and immunohistological examination of endometrial biopsies of performance mares to search for findings suggestive of an ovarian disorder and possible additional lesions that could impair fertility.

In this study, endometrial biopsies collected from 152 performance mares were investigated. The sport mares of this study had participated in tournaments of class M, S or in international competitions. The time duration between the retirement from sports and the collection of the endometrial biopsy was reported as "less than 1 year", "1 year" and "2 or more years". The age of the performance mares ranged between 6 and 20 years (average age: 13 years). The biopsies had been submitted as formalin-fixed specimens to the Institute of Veterinary Pathology, University of Leipzig between 1994 and 2012 . Biopsies of all mares $(n=152)$ were examined to diagnose endometrosis and endometritis (Schoon et al. 1997). Moreover, biopsies of mares that were collected during the breeding season $(n=82)$ were investigated for the presence of the main two forms of differentiation disorders, i.e. glandular inactivity and irregular maldifferentiation. To verify the presence of an irregular maldifferentiation, selected cases $(n=24)$ were immunostained using antibodies detecting progesterone and oestrogen receptors. Semiquantitative analysis of the immunosignal was performed using an immunoreactive score and variance analysis.

Seventy-four percent (113/152) of performance mares had degenerative glandular lesions consistent with endometrosis, these were mild in 64, moderate in 43 and marked in 6 mares. In $28 \%$ (42/152) of the mares, endometrial inflammation was observed. Endometritis was mild in 34, moderate in 7 and marked 1 mare. Differentiation disorders were detected in 40 of 82 (49\%) mares during the breeding season including glandular inactivity in 8 mares, and an irregular glandular differentiation in 32 mares. In regard to the mares ( $\mathrm{n}=32$ ) with an irregular glandular differentiation, 10 showed an irregular proliferative differentiation, 15 an irregular secretory differentiation and 7 mares a completely irregular differentiation. The irregular glandular differentiation was confirmed by immunohistochemistry. Irregularly differentiated endometria showed an abnormal steroid hormone receptor expression, characterized by a high intra- and inter- 
glandular variance of the immunoreaction. Notably, during the breeding season, the type of predominantly observed differentiation disorder varied depending on the time duration between the mare's retirement from sports and the biopsy collection. Glandular inactivity occurred mostly in mares that had retired less than 1 year ago (5 of 8 mares with glandular inactivity); none of the mares that had spent 2 or more years out of sports showed this endometrial differentiation disorder. An irregular proliferative differentiation was seen most frequently in mares having completed their sports career less than 1 year ago $(4$ of 31 ; 13\%) and approximately 1 year ago $(5$ of 32 ; $16 \%)$. An increase in the incidence of an irregular secretory differentiation was diagnosed from mares having retired less than one year ago (7\%; 2 of 31$)$ to those having completed their sport career around 1 year ago (19\%; 6 of 32); the irregular secretory glandular morphology was most commonly observed in mares that had spent 2 or more years out of sports $(37 \% ; 7$ of 19).

The diagnosed inflammatory and degenerative endometrial alterations were predominantly mild to moderate. Therefore, the presence of solely these alterations could not explain the clinically observed reduced fertility of sports mares. Interestingly, a high number of performance mares with differentiation disorders of the endometrium during the breeding season were observed. This was in contrast to the numbers of mares with endometrial differentiation disorders reported in the literature (7-10\%), the latter refers to endometrial biopsies of different types of mares including broodmares. Furthermore, an association between the type of the endometrial differentiation disorder and the time duration between the completion of a mare's sports career and the biopsy retrieval was noted, i.e. glandular inactivity was only observed in mares that had retired recently. Glandular inactivity as well as an irregular glandular differentiation is most commonly caused by an ovarian dysfunction. This is described in horses and in human beings. Both forms of a differentiation disorder, however, may also occur without detectable underlying cause. In summary, results of this study suggest that hormonal imbalances (most likely related to ovarian dysfunction) are responsible for endometrial differentiation disorders, leading to subfertility in performance mares. Further clinical studies are needed that investigate the ovarian function of sport mares.

\title{
Potential usefulness of Anti-Muellerian-Hormone (AMH) for assisted repro- duction techniques in the mare
}

\author{
A. Vernunft \\ Institute of Reproductive Biology, Leibniz Institut for Farm Animal Biology, Dummerstorf
}

Correspondence: vernunft@fbn-dummerstorf.de

In females Anti-Muellerian hormone (AMH) is produced only from granulosa cells, manly expressed from preantral, secondary follicles during follicle recruitment. Therefore it is used as an independent endocrine marker for this pool of small gonadotropin responsive follicles, which are also termed the ovarian follicular reserve. In human medicine the parameter AMH is used in assistant reproductive techniques to predict the menopause, to prevent hyperstimulation syndrome of the patients and to calculate an individual FSH dose in a superstimulation protocol. But the knowledge about $\mathrm{AMH}$ in horses is very rare. In recent publications the role of $\mathrm{AMH}$ for identifying granulosa cell tumors in mares or for cryptorchidism in stallions is described. But there is a lack of information of the role of AMH for follicular development under the special endocrine situation in mares or the potential usefulness of AMH for assisted reproduction techniques in horses. With our recent work, we wanted to provide knowledge on this specific field.

One of our studies aimed to determine AMH levels in follicular fluid of tertiary follicles and to investigate their relationships to antral follicle development in mares. Therefore, fluids of follicles in different developmental stages were obtained by repeated, transvaginal ultrasound guided-follicle aspirations from 8 mares during dioestrus and from preovulatory follicles (after hCG-inducted ovulation) during oestrus. AMH concentrations of follicular fluids were determined with a human ELISA Kit (DSL-10-144400). Subsequently, the relations between AMH-, 17ß-estradiol-, progesterone- and IGF-1 concentrations in the follicular fluids as well as relations to follicular size and developmental stage were studied. Data showed significant negative correlations between intra follicular concentrations of $\mathrm{AMH}$ and $17 \mathrm{~B}$-estradiol $(r=-0.58 ; p<0.0001)$ as well as between $\mathrm{AMH}$ and follicle diameter $(r=-0.76 ; p<0.001)$, but not between $\mathrm{AMH}$ and progesterone or IGF-1. Based on the observed dynamic changes of AMH secretion in large antral follicles during follicle development, a regulatory involvement of $\mathrm{AMH}$ in equine follicle development is likely by an estrogenesis modification in mares.

The aim of another study of our group was to describe AMH levels in equine plasma and their relationship to follicular growth in mares. We chose 4 mares, out of 12 oocyte donor mares (after weekly repeated ultrasound guided follicles aspiration sessions), which had developed constantly a high number of follicles between the aspiration sessions (average of $11.1 \pm 1.1$ follicles per session) and 4 mares, which showed constantly low numbers of new grown follicles (6.2 \pm 0.5 follicles) between the weekly aspiration sessions. Plasma $\mathrm{AMH}$ levels were measured in blood samples, which were taken from each mare at five consecutive follicle aspiration sessions. Mares with many new grown follicles had significant higher plasma AMH levels $(1.2 \pm 0.05 \mathrm{ng} / \mathrm{ml})$ compared to mares with a lower number of new grown follicles $(0.6 \pm 0.04 \mathrm{ng} / \mathrm{ml} ; \mathrm{p}<0.001)$. Individual $\mathrm{AMH}$ levels remained at a constant level during the observed period in each mare. We concluded that plasma AMH levels can be used to predict the number of available follicles in a follicle aspiration program in mares and therefore it could be also a marker to calculate the ovarian follicular reserve in mares.

In conclusion, our results implicate that intrafollicular $\mathrm{AMH}$ could be involved in dominant follicle development as an inhibiting factor and that $\mathrm{AMH}$ levels in plasma can be used as a marker of the ovarian follicular reserve in mares. Due to species-specific features, the results should be discussed considering their potential relevance to a controlled superovulation in mares. 